REVIEW ARTICLE

AFRICAN JOURNAL OF CLINICAL AND EXPERIMENTAL MICROBIOLOGY SEPTEMBER 2013 ISBN 1595-689X VOL14 No.3

AJCEM/132

http://www.ajol.info/journals/ajcem

COPYRIGHT 2013

AFR. J. CLN. EXPER. MICROBIOL. 14(3): 146-154. http:/ / dx.doi.org/10.4314/ajcem.v14i3.5

\title{
PREVALENCE OF METHICILLIN-RESISTANT STAPHYLOCOCCUS AUREUS IN SAUDI ARABIA: SYSTEMIC REVIEW AND META-ANALYSIS
}

\author{
Sulaiman A. AL Yousef*, Sabry Y. Mahmoud, Eihab, M. Taha \\ *Correspondence: Department of Medical Laboratory Sciences, College of Applied Medical Science, University of \\ Dammam, P.O. Box 1683 Hafr Al Batin - 31991 (Saudi Arabia). Email; saalyousef@ud.edu.sa
}

\begin{abstract}
\section{INTRODUCTION}

$S$. aureus is a versatile human pathogen that causes diseases ranging from mild infection of the skin to life threatening sepsis (1). After introduction of penicillin in 1940, penicillinase-producing S.aureus were detected, leading to development of penicillinaseresistant semi-synthetic penicillins as methicillin and oxacillin. Within a year from this, MRSA were reported in United Kingdom (2). The emergence of strains resistant to methicillin and other antimicrobial agents has become major concern because of the higher mortality due to systemic MRSA infections (3).

Although the rates of isolation of MRSA have been increasing throughout the world for the last decades and in some areas the rates reached $>50 \%$, there are considerable variations in the prevalence of MRSA according of geographic area $(4,5,6)$.

KSA covers over 2 million $\mathrm{Km}^{2}$ area and estimated population over 27 million and considered potentially hot spot for the collection of MRSA because up to 6 million of their populations are expatriates from many countries. In addition, KSA hosts about four million Muslim pilgrims from all over the world (7). KSA studies in the early 1990s consistently found low MRSA prevalence (5\% and $7.5 \%$ ) which increased dramatically up to $91 \%$ after 1995 (8). This study aims to determine average MRSA prevalence in KSA hospitals by conducting a systemic review and metaanalysis.
\end{abstract}

In recent years, methicillin-resistant Staphylococcucs aureus (MRSA) have become a truly global challenge. Systemic review and meta-analysis was performed to summarize the prevalence of MRSA in different regions of Kingdom of Saudi Arabia (KSA). A search of the PubMed, Google and Google Scholar databases for studies published during the period of 1 January 2002 through 31 December 2012 was conducted. We included studies that looked at the number and prevalence of MRSA among total S. aureus. Meta-analyst and comprehensive meta-analysis were used for statistical analysis. Twenty six studies were included in the review, representing five regions of KSA. Pooled estimation of 22,793 S. aureus strains showed $35.6 \%$ (95\% Confidence interval (CI), 0.28 $0.42 ; \mathrm{P}<0.01$ ) of the strains were MRSA with significant heterogeneity. Prevalence of MRSA ranged from $5.97 \%$ to $94 \%$ in Dahran and Riyadh cities, respectively. MRSA proportion among KSA regions is slightly high and varied from one city to the other.

Key words: Saudi - methicillin-resistant Staphylococcucs aureus -systemic review.

\section{MATERIALS AND METHODS}

Data acquisition: literature search was conducted in the PubMed and Google Scholar database for the time period spanning January 2002 to December 2012. The search strategy used keywords (and combinations thereof) "Staphylococcus aureus", "S. aureus", "Prevalence", "Methecillin"," Methecillin-resistant Staphylococcus aureus", "MRSA" and "Saudi Arabia". Additionally, abstract book of International congress on infectious Diseases was explored.

Inclusion and exclusion criteria:

The following features were included in the study:
1- S. aureus samples were collected from Saudi hospitals.

2- . Prevalence of infection or colonization with MRSA in patients or residents in clinical and nursing healthcare settings was reported.

Studies were excluded for the following reasons:

1- There were $\leq 2$ cases of MRSA bacteremia reported.

2- The study described results that used previously published data with $>1$ year of overlap or $75 \%$ time overlap between studies (in these cases, one representative study was chosen).

3- . Samples were partially/totally selected from MRSA culture collections. 4. Studies failed to focus on MRSA prevalence (these included studies those mixed results of " coagulase-negative Staphylococcus and S. aureus or healthy people and patients, estimating MRSA transmission, or The therapeutic efficacy

\section{Data extraction}

A data extraction form was developed to collect information from MRSA prevalence studies. This included study location, study period, specimens and/or sites, number of patients or specimens, and results present in form of proportions (express as the percentage of MRSA cases among isolates of S.aureus. Statistical analysis

Statistical analysis was performed by the use of Metaanalyst (version 3.13 Beta) and Comprehensive MetaAnalysis (version 2.0) software. By using Meta-Analyst, overall proportion of MRSA in Saudi was pooled by forest plot with $95 \%$ confidence interval $(95 \% \mathrm{CI})$. The $\mathrm{Q}$ statistic for homogeneity and the $\mathrm{I}^{2}$ test were calculated to assess whether results varied no more than might have been expected by the play of chance 
(random sampling). A significant heterogeneity was considered for $\mathrm{P}<0.10$ and $\mathrm{I}^{2}>50 \%$ (9). The small study bias was measured by Begg's funnel plot and by the Egger test $(10,11)$.

\section{RESULTS}

From January 2002 through December 2012, Twenty six published articles that matched inclusion criteria were selected for meta-analysis (12 - 37). Among these publications which reported the prevalence of MRSA in KSA, twenty five studies were represented five regions only (from thirteen total regions of KSA) and one study did not reported location (submitted as KSA) (Table 1). Study duration varied between 4 and 96 months whereas one and five days study period were reported in two publications $(23,30)$. Most studies, screening was performed as multi-site swabbing, most often by additional swabs taken from skin lesions, nasal or wounds. While three studies did not mentioned screening sites only clinical specimen or pediatric and adult population reported $(15,16,19)$.

As shown in Forest plot (Figure,1) sample size and 95\% CI of each study was reported. Additionally, pooled estimation (Overall) of 22793 S.aureus showed 35.6\% (95\% CI, $0.28-0.42 ; \mathrm{P}<0.01$ ) of strain to be MRSA. There was a high level of heterogeneity, random model methods $(\mathrm{I} 2=100 \%, \mathrm{P}<0.001)$. According to Begg and Mazumdar rank correlation test, a significant correlation suggests that bias exists but does not directly address the implications of this bias (Kindall $\mathrm{s}$ tau $=-0.11$ ) with a 1-tailed P-value $=0.20$.

MRSA proportions variation ranged from $5.97 \%$ to 94.59\% in Dahran and Riyadh cities, respectively $(14,33)$. Average proportion of MRSA in different KSA regions reported that, $\mathrm{Al}$-Gouf recorded $<15 \%$ in contrast to highest prevalence in Assir and Riyadh (40\%-60\%) respectively. Makkah was positioned in intermediate value $(25 \%-40 \%)$ as MRSA prevalence (Figure, 2). 


\begin{tabular}{|c|c|c|c|c|c|c|c|c|c|c|c|c|c|c|c|c|c|}
\hline 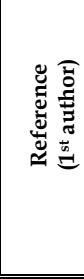 & & 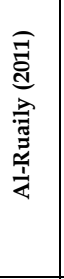 & 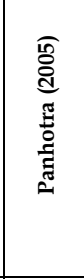 & 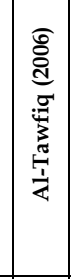 & 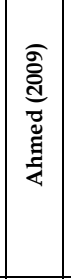 & 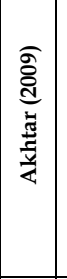 & 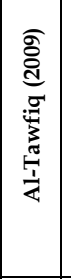 & 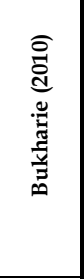 & 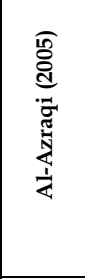 & 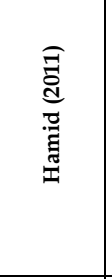 & 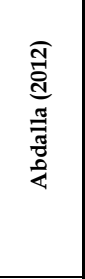 & 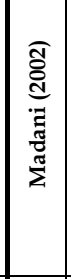 & 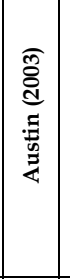 & 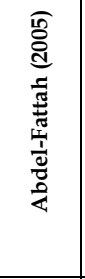 & 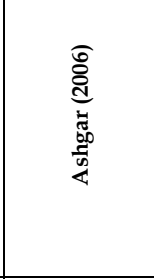 & 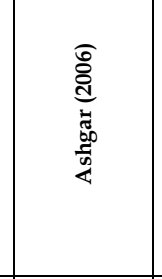 & 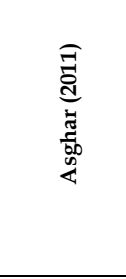 \\
\hline 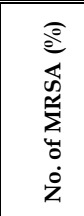 & & $\widehat{\widehat{m}}$ & 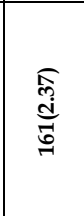 & 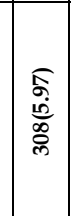 & 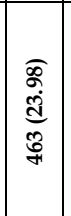 & 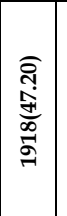 & 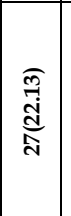 & 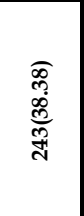 & 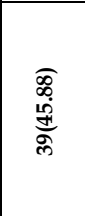 & $\frac{*}{\frac{*}{00}}$ & 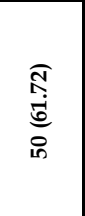 & $\mid$\begin{tabular}{c|}
$\overline{\tilde{s}}$ \\
$\infty$ \\
$\infty$ \\
$\tilde{0}$ \\
$\bar{\exists}$
\end{tabular} & 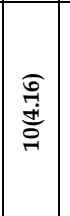 & 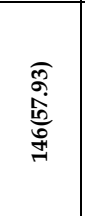 & 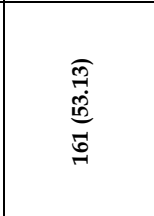 & 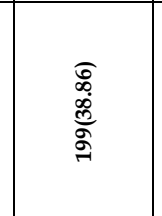 & 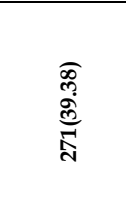 \\
\hline 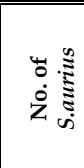 & & 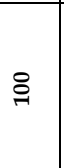 & ర్రి & $\begin{array}{l}\text { U. } \\
\text { in }\end{array}$ & 兽 & 菅 & $\Xi$ & ஜ & $\mathscr{\infty}$ & ڤั & $\vec{\infty}$ & ลี & 강 & ฟิ & ల్లి & ถี & $\stackrel{\infty}{\infty}$ \\
\hline 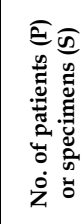 & & $\begin{array}{l}\frac{\pi}{n} \\
\bar{\sigma}\end{array}$ & ' & . & & 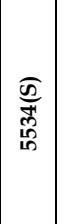 & $\begin{array}{l}\bar{\Xi} \\
\overline{0} \\
\bar{z}\end{array}$ & ' & ' & 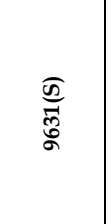 & $\widehat{E}$ & 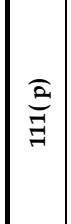 & 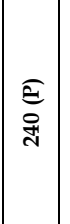 & 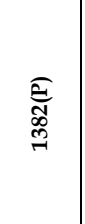 & $\begin{array}{l}\overline{0} \\
\stackrel{0}{0} \\
\text { d. }\end{array}$ & 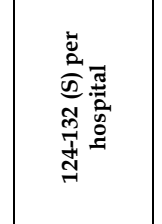 & $\begin{array}{l}\hat{E} \\
\stackrel{E}{\infty} \\
\stackrel{\sim}{=}\end{array}$ \\
\hline 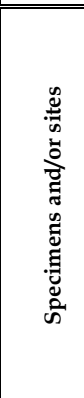 & & 苛 & 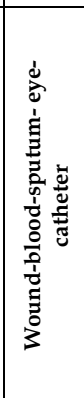 & 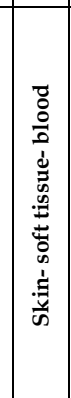 & 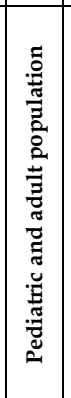 & 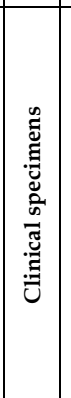 & $\begin{array}{l}\widetilde{\delta} \\
\frac{0}{\infty}\end{array}$ & 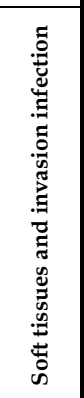 & 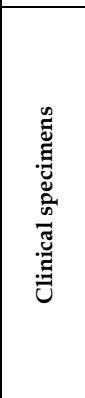 & 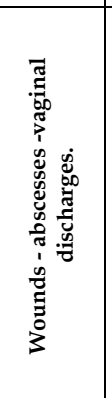 & 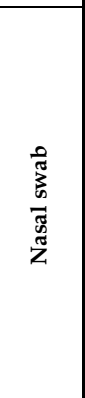 & 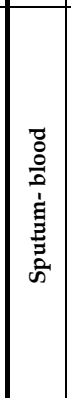 & 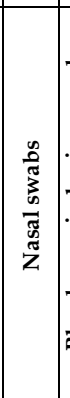 & 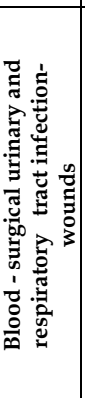 & $\begin{array}{l}\widetilde{\sigma} \\
\stackrel{\circ}{\oplus}\end{array}$ & 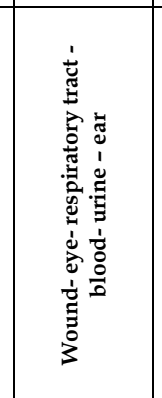 & 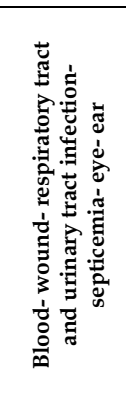 \\
\hline 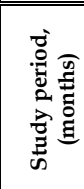 & & 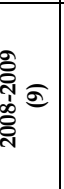 & $\begin{array}{l}\text { 突 } \\
\text { S̆ } \\
\text { gे }\end{array}$ & 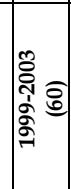 & 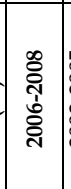 & 迢 & 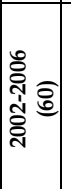 & 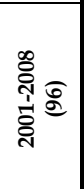 & 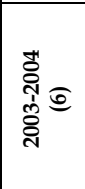 & ఫ్రై & $\overrightarrow{\text { ते }}$ & 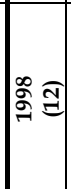 & 命 & ఫ్రై & 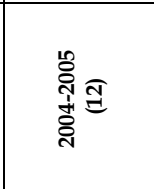 & 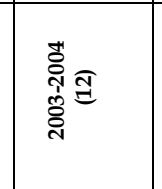 & 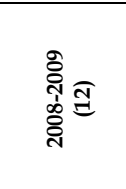 \\
\hline 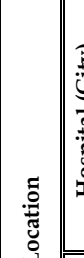 & 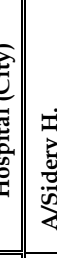 & 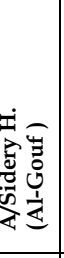 & 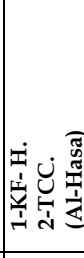 & 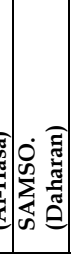 & 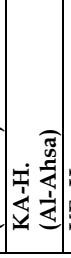 & & 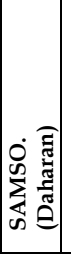 & 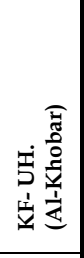 & 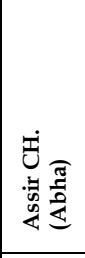 & 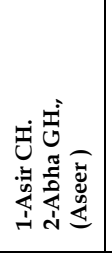 & 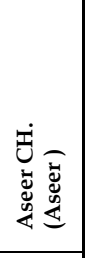 & 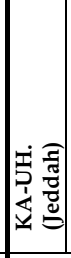 & & 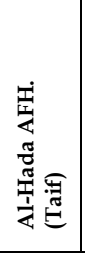 & 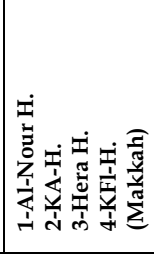 & 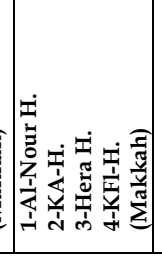 & 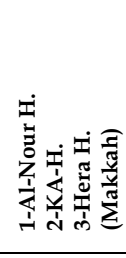 \\
\hline 6 & 若 & 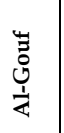 & & & & $\frac{\pi}{4}$ & & & & 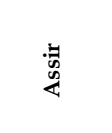 & & & & & 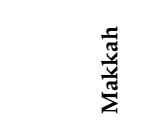 & & \\
\hline
\end{tabular}




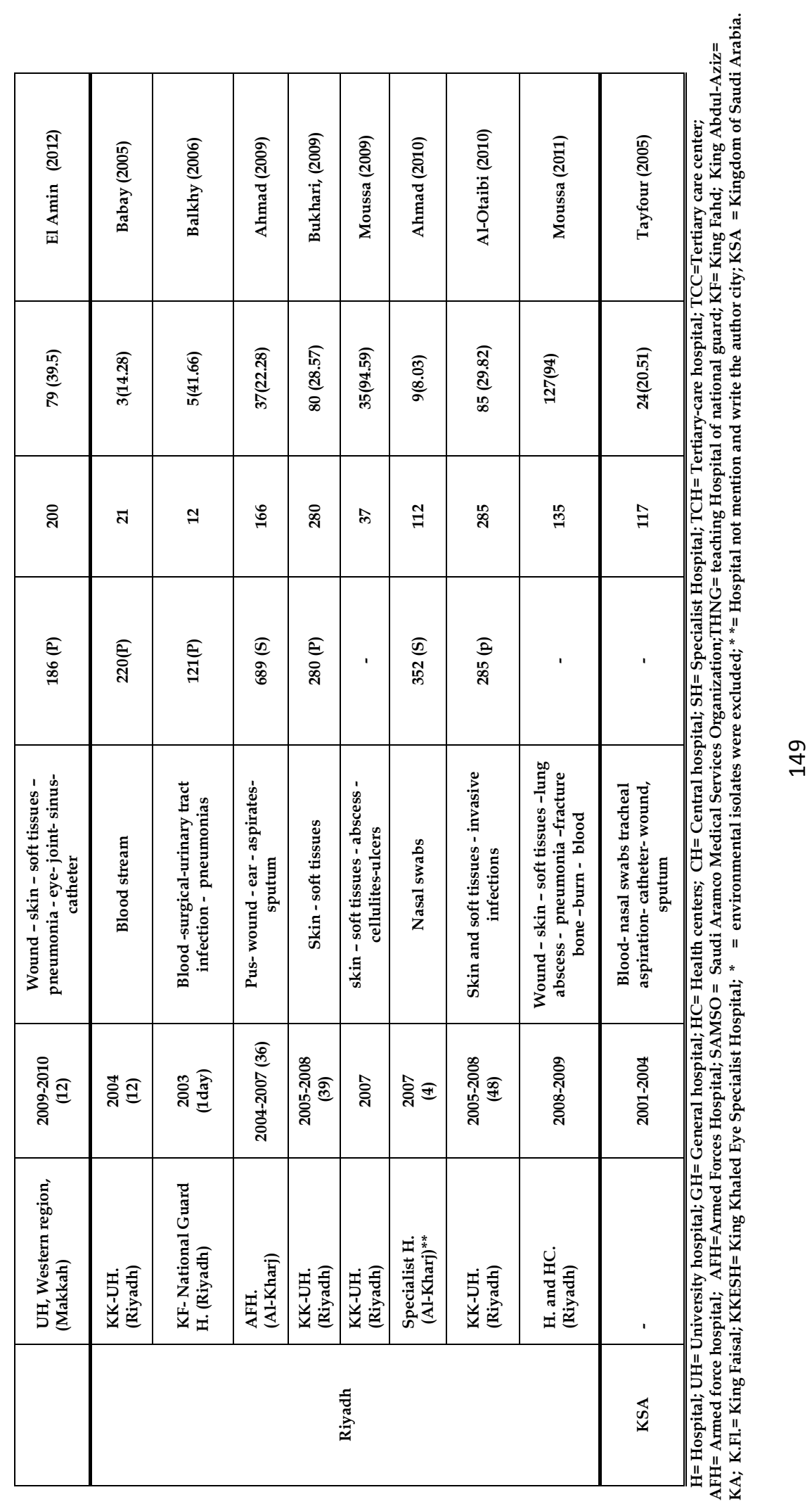


Studies

RL-Pusily <2011

Pantinta (2075)

A2-Tsutia 12006

Ahrmed (2009)

Ahthe $\{2009)$

2.- Trawtio $(2009)$

Qublarso (2010)

Al-Azraq 12005

Harid $(2011)$

Abdalla $\{2012\}$

Madani (2002)

Nuoton [2003)

Abdet-Fatlah [2005

Ashyar (2005)

Ashase (2005)

haghar (2011)

El Amin (2012)

Babay 12005:

Balksy [2005]

Ahmad (bone

Bukbari (2000)

Mounsa (2009)

Ahrnod (2010)

2i-Otasiot (2010)

Moussa patisy

Tayseur (2005)

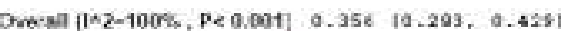

Batinate $695 \mathrm{~s}$ C.I.

8.230 16.066, 9.196)

a.,924 id .025, a, 033

$3.06010 .052,0.066$

$0,200,10,222,0.259$

6.472 [4.-453, a.467

c. 221 10.143, 0.295!

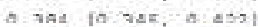

Q. $45910.35 x, 0.563 \mid$

9.520 19.298, 9, 98p ।

0.612 10.511, 9.722

ब.330 16.329, 0.430।

a.dsz 10,016 , a.dacs

$0.57910 .523,0.640)$

$9.521,10.425,9.5021$

6.798 10. $255: 0.45$

9.234 10.255, 9.425!

a. $39519,327,0,463$ )

$0.14310 .005,0.2921$

9. 417 19.125, 9.695

$0.22510 .162,0.266$

a. 206 10.223, a.220

6. 946 10;973 1, 000인

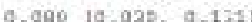

c. 298 id. $245,0.355$;

b. $7 \pm 1$ fo $4 n t, a$ ant

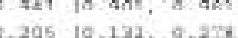

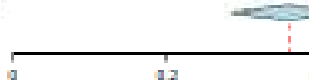

FIGURE 1: FOREST PLOT OF PROPORTION OF MRSA AMONG STAPHYLOCOCCUS AUREUS IN THE 26 SAUDI STUDIES, 2002-2012. 
FIGURE 2: PROPORTIONS VARIATION OF MRSA IN SAUDI ARABIA, 2002-2012.

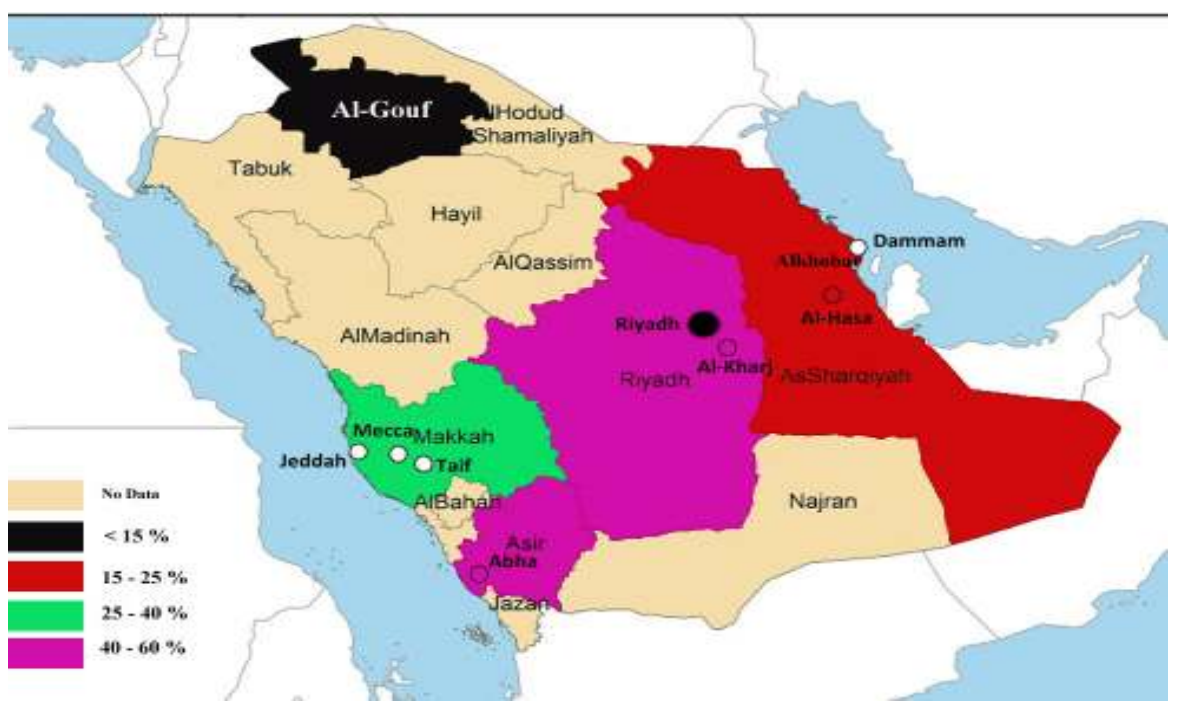




\section{DISCUSSION}

In this review, 26 studies on MRSA prevalence in different KSA regions were analyzed since 2002 to 2012. We summarized the cumulative prevalence of MRSA and supplied a map to explain the epidemiology of MRSA in Saudi.

According to our study, the overall estimation of MRSA prevalence in Saudi was 35.6\% (95\% CI, 0.28 0.42). whereas MRSA prevalence mean was different from region to another (Figure, 2). While, variation in MRSA proportion exists in several cities $(5.97 \%$ to 94\%). As we know, meta-analysis studies for MRSA prevalence in KSA are not reported but some studies mentioned MRSA average. MRSA proportion from KSA peer-reviewed studies between 1993 and 1997 is low (5-10\%) (38). Recently, MRSA prevalence in Saudi is closely with our data where detected $29.9 \%$ from January 1990 through April 2011 (39). This finding indicates that temporal increases in MRSA prevalence in KSA. One major factor that could drive regional MRSA dissemination could be the ineffective of infection prevention. Although the reasons for variation of MRSA proportion in KSA cities are unknown, Van Belkum et al have looked at the clonal distribution of MRSA in various part of KSA and found that a single clone account $93 \%$ of examined isolates. Therefore it seems that difference in the incidence of MRSA reflects host or environmental factors (40). Additionally, high variation may be due to epidemiology of MRSA is in transition period and infection control rules may be most effective (41). In regional perspective, Saudi has a higher prevalence of

\section{REFERENCES}

1- Lowy, F. D. Staphylococcus aureus infections. N. Engl. J. Med. 1998; 339: 520-532.

1. Jevons, M. P. Celbenin-resistant Staphylococci. British Medical J. 1961; $1924-$ 1925.

2. Witte, W., Kresken, M., Braulke, C. and Cuny, C. Increasing incidence and widespread dissemination of methicillinresistant Staphylococcus aureus (MRSA) in hospitals in central Europe, with special reference to German hospitals. Clin. Microbiol. Infect. 1997; 3: 414-422.

3. Bell, J. M., and Turnidge, J. D. High prevalence of oxacillinresistant Staphylococcus aureus isolates from hospitalized patients in Asia-Pacific and

South Africa: results from SENTRY Antimicrobial Surveillance Program, 19981999. Antimicrob. Agents Chemother. 2002; 46:879-881.

4. European Antimicrobial Resistance Surveillance System. EARSS annual report 2006. European Antimicrobial Resistance
MRSA than Bahrain, Kuwait, and Lebanon countries. In contrast, MRSA prevalence in Egypt, Oman, Iran and Jordan was reported more than $50 \%(39,42,43)$. From an international stand, the mean incidence of MRSA across China was over 50\% and in Shanghi, the prevalence was over $80 \%$ (44). In Spain, the prevalence of MRSA was 29.2\% (45).

Limitations of the study

1- The studies we review contain data about different patient population (up to six million of whom are expatriates mainly from south and east Asia beside annually a host of Muslim pilgrims)

2- Only five KSA regions which cannot fully represent Saudi was pooled data

3- Due to limited access to in-press articles and theses, some studies might been missed beside low number of MRSA prevalence studies in KSA (26 studies).

\section{Conclusion}

Our study showed that MRSA proportion among KSA studies is slightly high and varied from one city to the other. Thus, to combat the MRSA dissemination, public health researchers and all health professionals must understand the role of hospital hygiene protocols and of antimicrobial drug policies, as well as mechanisms of regional spread of MRSA throughout hospitals. Future systematic reviews would also ideally be based on a greater number of studies that are of high quality.

Surveillance System, Bilthoven, The Netherlands.

5. National Nosocomial Infections Surveillance (NNIS) System Report. Data summary from January 1992 to June 2002. Am. J. Infect. Control. 2002; 30:458-475.

6. Memish, Z. A. The hajj: communicable and non-communicable health hazards and current guidance for pilgrims. Euro. Surveill. 2010; 15: 19671.

7. Yezli, S., Shibl, A. M., Livermore, D. M. and Memish, Z.A. Antimicrobial resistance among gram-positive pathogens in Saudi Arabia. J. chemotherapy. 2012.24(3): 125-136.

8. Higgins J. P. T., and Green, S. Cochrane Handbook for Systematic Reviews of Interventions (eds). 4.2.5 [updated May 2005]. In: The Cochrane Library, Issue 3, 2005. Chichester: John Wiley \& Sons, Ltd 2005.

9. Begg, C. B., and Mazumdar, M. Operating characteristics of a rank correlation test for publication bias. Biometrics. 1994; 50: 1088101. 
10. Egger, M., Davey, S. G. and Schneider, M. Bias in meta-analysis detected by a simple, graphical test. B. M. J. 1997; 315:629-634.

11. Al-Ruaily, M. A., and Khalil, O. M. Detection of (mecA) gene in methicillin resistant Staphylococcus aureus (MRSA) at prince A / Rhmansidery hospital, Al-jouf, Saudi Arabia. Journal of Medical Genetics and Genomics. 2011; 3(3): 41-45.

12. Panhotra, B. R., Saxena, A. K. and AlMulhim, A. S. Chloramphenicol susceptible methicillin resistant Staphylococcus aureus in eastern region of Saudi Arabia. Saudi Med. J. 2005; 26(7): 1149-1151.

13. Al-Tawfiq, J. A. Incidence and epidemiology of methecillin-resistant Staphylococcus aureus infection in a Saudi Arabian hospital, 19992003. Infect. Control Hosp. Epidemiol. 2006; 27(10): 1137-1139.

14. Ahmed, M.U., Ahmed, M. and Yiannakou, N. MRSA (methicillin resistant Staphylococcus aureus) and MSSA (methicillin sensitive Staphylococcus aureus) and their antibiotic activity pattern in eastern region of Saudi Arabia. Ann. Abbassi Shaheed Hosp. Karachi Med. Dent. Coll. 2009; 14 (2): 88-96.

15. Akhtar, N., Alzahrani, A., Obeid, O. and Dassal, D..In vitro ciprofloxacin resistance patterns of gram-positive bacteria isolated from clinical specimens in a teaching hospital in Saudi Arabia. J. Ayub. Med. Coll. Abbottabad. 2009; 21(3): 54-56.

16. Al-Tawfiq, J. A., and Abed, M. S. Prevalence and antimicrobial resistance of health care associated bloodstream infections at a general hospital in Saudi Arabia. Saudi Med. J. 2009; 30(9): 1213-1218.

17. Bukharie, H. A. Increasing threat of community-acqired methicillin-resistant Staphylococcus aureus. Am. J. Med. Sci. 2010.340(5): 378-381.

18. Al-Azraqi, T., and Bello, C. S. S. Characterization of nosocomial MRSA in Assir central hospital, Abha, Kingdom of Saudi Arabia. Afr. J. Clin. Exper. Microbiol. 2005; 6(2): 163-166.

19. Hamid, M. E. Resistance pattern of coagulase positive Staphylococcus aureusclinical isolates from Asir region, kingdom of Saudi Arabia. Journal of Microbiology and Antimicrobials. 2011; 3(4): 102-108.

20. Abdalla, N. M., Haimour, W. O. Osman, A. A. and Abdulaziz, H. Assessment of the multifactorial effect on antimicrobial sensitivity in positive staphylococcus aureus clinical isolates from Assir region, Saudi Arabia. J. Medicine. 2012; 13: 152-159.
21. Madani, T. A., Epidemiology and clinical features of methicillin-resistant Staphylococcus aureus in the University Hospital, Jeddah, Saudi Arabia. Can. J. Infect. Dis. 2002; 13(4): 245-250.

22. Austin, T. W., Austin, M. A., McAlear, D. E., Coleman, B. T. Osoba, A. O. Thaqafi, A. O. and Lamfon, M. A. MRSA prevalence in a teaching hospital in Western Saudi Arabia. Saudi Med. J. 2003; 24(12): 1313-1316.

23. Abdel-Fattah, M. M. Surveillance of nosocomial infections at a Saudi Arabian military hospital for a one-year period. GMS Ger. Med. Sci. 2005; (3):Doc06.

24. Asghar, A. H. Frequency and antimicrobial susceptibility patterns of bacterial pathogens isolated from septicemic patients in Makkah hospitals. Saudi Med. J. 2006; 27(3):361-367.

25. Asghar, A. H., and Momenah, A .M. Methicillin resistance among Staphylococcus aureus isolates from Saudi hospitals. Med. Princ. Pract. 2006; 15: 52-55

26. Asghar, A. H. Frequency and antibiotic susceptibility of gram positive bacteria in Makkah hospitals. Ann. Saudi Med. 2011; 31(5): 462-468.

27. El Amin, N. M. and Faidah, H. S. Methicillinresistant staphylococcus aureus in the western region of Saudi Arabia : prevalence and antibiotic susceptibility pattern. Ann. Saudi Med. 2012; 32(5): 513-516.

28. Babay, H. A., Twum-Danso, K., Kambal, A. M. and Al-Otaibi. F. E. Bloodstream infections in pediatric patients. Saudi Med. J. 2005; 26:1555-61.

29. Balkhy, H. H., Cunningham, G., Chew, F. K., Francis, C., Al Nakhli, D. J. and Almuneef, M.A. Hospital- and community-acquired infections: a point prevalence and risk factors survey in a tertiary care center in Saudi Arabia. Int. J. Infect. Dis. 2006; 10: 32633.

30. Ahmad, S., Alenzi, F. Q., Al-Juaid, N. F. and Ahmed, S. Prevalence and antibiotic susceptibility pattern of Methicillin Resistant Staphylococcus aureus at Armed Forces Hospital in Saudi Arabia. Bangladesh Med. Res. Counc. Bull. 2009; 35(1): 28-30.

31. Bukhari, E. and Al-Otaibi, F. Severe community acquired infections caused by methicillin resistant Staphylococcus aureus in Saudi Arabian children. Saudi Med. J. 2009; 30(12): 1595-600.

32. Moussa, I. M. and Shibl, A. M. Molecular characterization of methecillin-resistant Staphylococcus aureus recovered from 
outpatient clinics in Riyadh, Saudi Arabia. Saudi Med. J. 2009; 30(5): 611-617.

33. Ahmad, S. The prevalence of Staphylococcus aureus colonization among Healthcare Workers at a Specialist Hospital in Saudi Arabia. Journal of Clinical and Diagnostic Research. 2010; 2438(4): 2438-2441.

34. Al-Otaibi, F. E. and Bukhari, E. E. Community- acquired methicillin- resistant Staphylococcus aureus in outpatient children assisted at university hospital in Saudi Arabia: A 3-year study (2005-2008). Journal of Pediatric Infectious Diseases. 2010; 5(4): 369-376.

35. Moussa, I. M. Finger printing of community acquired-methicillin resistance Staphylococcus aureus recovered from King Saudi Arabia. African Journal of Biotechnology. 2011; 10(53): 10939-10947.

36. Tayfour, M. A., Eris, N. F. N. and Alanazi, A.R. Comparison of antibiotic susceptibility tests, plasmid profiles and restriction enzyme analysis of plasmid DNA of methicillin susceptibility and resistantstaphylococcus aureus strain isolated from intensive care units. Saudi Med. J. 2005; 26(1): 57-63.

37. Rundmann, H., Aires-de-Sousa, M., Boyce, J. and Tiemersma, E. Emergence and resurgence of Methicillin-resistant Staphylococcus aureus as a public-health threat. The Lancet. 2006; 368 (9538): 847-885.

38. Aly, M., and Balkhy, H. H. The prevalence of antimicrobial resistance in clinical isolates from gulf corporation council countries. Antimicrobial resistance and infection control. 2012; 1-26.
39. Van Belkum, A., Vandenbergh, M., Kessie, G.,. Qadri, S. M. H, Lee, G., van den Braak, N., Verbrugh, H. and Al-Ahdal. M. N. Genetic homogeneity among methicillinresistant Staphylococcus aureus strains from Saudi Arabia. Microb. Drug Resist. 1997; 3: 365-369

40. Kotilainen, P., Routamaa, M., Peltonen, R., Oksi, J., Rintala, E., Meurman, O. Elimination of epidemic methicillin resistant Staphylococcus aureus from a university hospital and district institutions, Finland. Emerg. Infect. Dis. 2003; 9: 169-75.

41. Askari, E., Soleymani, F., Arianpoor, A., Tabatabai, S. M., Amini, A. and Nasab, M. N. Epidemiology of mecA-Methicillin Resistant Staphylococcus aureus in Iran: A Systematic Review and Meta-analysis. Iran. J. Basic Med. Sci. 2012;15( 5): 1010-1019.

42. Borg, M. A., de Kraker, M., Scicluna, E., van de Sande-Bruinsma, N., Tiemersma, E., Monen, J. and Grundmann, H. Prevalence of methicillin-resistant Staphylococcus aureus (MRSA) in invasive isolates from southern and eastern Mediterranean countries. J. Antimicrob. Chemoth. 2007; 60: 1310- 1315.

43. Wang, H., Liu, Y., Sun, H., Xu, Y., Xie, X., and Chen. M. In vitro activity of ceftobiprole, linezolid, tigecycline, and 23 other antimicrobial agents against Staphylococcus aureus isolates in China. Diagn. Microbiol. Infect. Dis. 2008; 62: 226-229.

44. Cuevas, O., Cercenado, E., Goyanes, M., Vindel, A., Trincado, P., Boquete, T., Marin, A. and Bouza, E. Staphylococcus spp. in Spain: present situationand evolution of the resistance to antimicrobials (1986-2006). Enferm. Infecc. Microbiol. Clin., 2008; 26: 269-277. 